\title{
Análise cartográfica do confronto presidencial PSDB - PT no Paraná: período 1998 - 2010
}

\author{
Omar Neto Fernandes Barros* \\ Neli Aparecida de Mello-Théry** \\ Hervé Théry
}

\section{Resumo}

O tema das eleições no Brasil é frequente em abordagens econômicas, sociológicas, históricas e geográficas, entretanto a utilização da cartografia como método de análise é bem menos utilizada. Para o desenvolvimento desse estudo adotou-se a metodologia da espacialização temática expressa pelo mapa e servimo-nos do Estado do Paraná como um microcosmo da realidade brasileira. No primeiro momento analisaram-se as eleições presidenciais no período 1989-1994, chegando finalmente ao confronto entre o PSDB e o PT nos pleitos seguintes. Os padrões territoriais revelados ao longo do tempo permitiram mostrar as tendências ideológicas do eleitorado.

Palavras-chave: Eleições; Geocartografia; Municípios; Partidos; Paraná-Brasil.

* Doutorado em Geografia pela Universidade de São Paulo e Professor Associado da Universidade Estadual de Londrina. (onbarros@uel.br)

** Doutorados em Geographie - Universite de Paris Ouest-Nanterre-La Defense e em Geografia Humana, pela Universidade de São Paulo.

Doutorado em Geografia pela Université Paris 1 (PanthéonSorbonne) e Habilitation à diriger des recherches, pela Université Paris X Nanterre. Atualmente é pesquisador do Centre National de la Recherche Scientifique e professor visitante da USP.

Geosul, Florianópolis, v. 28, n. 56, p 131-146, jul./dez. 2013 
BARROS, O.N.F. et al. Análise cartográfica do confronto presidencial ...

Cartographic analysis of the presidential confront between PSDB PT in Paraná state: period $1998-2010$

\section{Abstract}

The theme of elections in Brazil is frequent in economic, sociological, historical and geographical approaches are used in many interpretations but the use of cartography as a method of analysis is far less frequent. To develop this study we adopted a methodology of spatialization, expressed by maps, and used the state of Paraná as a microcosm of Brazilian reality. At first, we analyzing the presidential elections in the period 1989-1994, finally arrive to the confrontation between the PSDB and the PT in the following ballots. The territorial patterns revealed over time allowed us to demonstrate ideological tendencies of the electorate.

Key words: Elections; Geo-cartography; Municipalities; Political parties; Paraná-Brazil.

\section{Introdução}

O tema das eleições no Brasil é frequente na bibliografia de Ciências Sociais (AVELAR; WALTER, 2008; FLEISCHER, 2002 ,), sobretudo após o retorno do país à democracia. Abordagens econômicas, sociológicas, históricas e geográficas são utilizadas em várias escalas de interpretações (AMORIM; PASSOS, 2005; BORGES, 2010; GAJARDONI, 2002), entretanto a utilização da cartografia como método de análise é bem menos frequente (JACOB et al., 2000; JACOB et al., 2009; MARCHAL; THÉRY; WANIEZ, 1992; SOARES; TERRON, 2008). No número especial da Revista Opinião Público de novembro de 2007 que tratou do estudo eleitoral brasileiro de 2002 e 2006, dos sete artigos publicados nenhum utiliza a cartografia como método de estudo, ou até mesmo como simples forma de ilustração. No livro Eleitores e representação partidária no Brasil de Kinzo e Braga (2007) nos 
BARROS, O.N.F. et al. Análise cartográfica do confronto presidencial ...

nove capítulos a linguagem cartográfica também é desconsiderada, e destacam-se análises regionalizadas em dois deles. No campo da cartografia eleitoral brasileira devem ser ressaltados os diversos trabalhos desenvolvidos pela equipe do Professor Cesar Romero Jacó da PUC-Rio em colaboração com o Professor Philippe Waniez da Universidade de Bordeaux - França, bem como o estudo de Soares e Terron (2008) sobre a geografia eleitoral da reeleição de Lula. Nesse artigo propomos um esforço no sentido de utilizar a cartografia como método de análise e difundi-la entre os leitores de ciências sociais. Para isto, servimo-nos do Estado do Paraná como um microcosmo da realidade brasileira. Após analisar as eleições presidenciais no período 1989-1994, o confronto entre o PSDB e o PT é abordado nos pleitos seguintes.

\section{A metodologia adotada}

Para o desenvolvimento desse estudo adotou-se a metodologia da espacialização temática expressa pelo mapa como "um meio de registro, de pesquisa e de comunicação dos resultados obtidos em seus estudos e não apenas como mera ilustração" (MARTINELLI, 2010, p.11). Embora muitos críticos da cartografia a considerem potencialmente alienadora no processo de conhecimento geográfico (KATUTA, 2005), são sem dúvida expressiva os trabalhos atuais que se utilizam desse ramo do conhecimento como método de estudo. $\mathrm{Na}$ apresentação do Atlas do Brasil: Disparidades e Dinâmicas do Território de Théry e Mello (2008 p.7), Wanderley Messias da Costa, professor titular de Geografia da Faculdade de Filosofia, Letras e Ciências Humanas da USP declara:

"Quando, entretanto, o objetivo é o de utilizar-se da cartografia enquanto recurso de interpretação, pelo qual tenta-se apreender e expressar ideias, conceitos, teorias, e a inteligibilidade de processos complexos, procurando representá-los em seus significados diversos e principalmente em suas relações, projeções, tendências e 
BARROS, O.N.F. et al. Análise cartográfica do confronto presidencial ...

movimentos dominantes, então estamos diante não de uma técnica dentre tantas disponíveis, mas de um método que é certamente o mais genuíno e sofisticado dentre os instrumentos de análise de que dispõem os geógrafos para fazer a sua particular leitura do mundo, das regiões e dos lugares."

O mapa é no dizer de Martinelli (2010, p.21) "a expressão do raciocínio que seu autor empreende diante da realidade"; é também um método que revela uma dimensão que pode não ser visível nos dados brutos e a cartografia passa a ter um caráter heurístico, com grande poder de evocar e comunicar aspectos sócio-político-econômicos.

\section{As eleições presidenciais no Paraná: 1989-1994}

Logo após o período ditatorial de 1964 - 1985 as eleições presidenciais com sufrágio universal direto de 1989 passaram a ter um significado especial para o país. Era a primeira vez que a geração nascida nas décadas de cinquenta e sessenta iria votar. A população brasileira era composta por $55,6 \%$ de eleitores (82 milhões). Fernando Collor de Mello foi eleito com 53\% dos votos válidos, em um pleito que teve uma abstenção média de apenas $11,9 \%$, tendo a região sul contribuído com uma participação de 92,1\% do seu eleitorado. Quanto aos resultados da eleição, observando mapas contidos no trabalho de Marchal et al. (1992), referentes aos $1^{\circ}$ e $2^{\circ}$ turnos, o Brasil aparece regionalizado em seis grandes categorias. Cinco delas presentes na região sul, com dominância de votos pró-Brizola no Rio Grande do Sul, oestes de Santa Catarina e Paraná. No leste dos estados de Santa Catarina e Paraná, assim como no norte paranaense, a dominância de Collor foi marcante. Desse modo o Paraná parece representar um microcosmo do Brasil.

A disputa eleitoral de 1994, que deu a vitória a Fernando Henrique Cardoso (FHC) com 54,3\% dos votos válido é reconhecida por todos como aquela em que o candidato do PSDB 
BARROS, O.N.F. et al. Análise cartográfica do confronto presidencial ...

foi eleito já no primeiro turno, empurrado pelo grande sucesso do Plano Real e, que muito poucas chances deram ao candidato Lula do PT. Possivelmente outro elemento que facilitou a vitória de FHC foi a divisão dos votos da centro-esquerda entre ele e o próprio Lula, que na época apresentava um discurso radical contra o FMI e o Plano Real. No plano estadual foi evidente a vitória de FHC em termos gerais e com forte expressão na porcentagem dos votos na região norte do estado.

No período atual da política brasileira a bipolarização das eleições presidenciais tem sido uma constante. Ainda que ao longo dos pleitos surjam candidatos com certo potencial para a disputa do segundo lugar, nossa atenção estará essencialmente voltada ao confronto PSDB - PT dado serem esses os partidos que realmente apresentaram desempenho capaz de conduzir seus candidatos ao cargo de Presidente da República.

\section{Participação do eleitorado nas eleições presidenciais no Paraná}

Avaliar a taxa de abstenção é por si mesmo, um aspecto importante da realidade e dos dados políticos pós-regime militar no Brasil e da atualidade. O estado do Paraná na eleição de 1989, conforme assinalado por Marchal et al. (1992), revela uma diversidade de participação marcante. Na região central do estado e o vale do Ribeira de Iguape a abstenção chegou a 15,6\%; no oeste e sudoeste chegou a 16,7\% mas com maior percentual de votos válidos que a região central. Ao inverso, as porcentagens de abstenção atingiram as menores taxas $(7,6 \%)$ e maior grau de votos válidos $(94,5 \%)$ na região Metropolitana de Curitiba e em parte do Sul.

Em 1994 a abstenção média do país foi de 17,8\%, bem superior aos $11,9 \%$ da eleição de 1989 . Podemos especular que as mazelas do governo Collor tenham levado a certo descrédito com a via democrática para a resolução dos problemas políticos do país, causando menor interesse na participação eleitoral. Em 1998 a abstenção chegou aos valores excepcionais de 21,5\%. O 
BARROS, O.N.F. et al. Análise cartográfica do confronto presidencial ...

desinteresse pode estar vinculado, desta vez, às dificuldades econômicas que o Plano Real estava encontrando, com desvalorização da moeda e o pouco crescimento do mercado de trabalho. Para o Paraná, como em grande parte do Brasil, apesar das grandes diferenças percentuais nesse período, é possível observar uma relativa manutenção da distribuição territorial do percentual de abstenção (WANIEZ, 2002, p. 341). O estado apresentou nesse período valores de participação eleitoral sempre pouco superior a média nacional, salvo para 1998.

Diante do quadro de disputas eleitorais que o país viveu nas eleições presidenciais seguintes ao período 1989-1994, parece necessário verificar se as mesmas continuaram despertando o interesse do eleitorado e, se a geografia eleitoral paranaense ainda representa um microcosmo brasileiro.

Os quatro cartogramas da figura 1 foram concebidos de forma a manter na legenda as mesmas classes de intervalos para permitir uma comparação imediata, revelando a evolução temporal e espacial dos valores do percentual de abstenção. Na primeira classe aparecem os valores de mínimo até $10 \%$, na segunda entre $10-20 \%$, na terceira entre 20 e $30 \%$ e, na quarta entre 30 e o máximo.

Os percentuais de abstenção globais médios para o Paraná nas eleições presidenciais, no período, 1998 - 2010 foram: $24,8 \%$ (amplitude 8,90 - 41,40) em 1998; 19,1\% (5,52 - 40,95) em 2002; $18,3 \%(8,25$ - 36,02) em 2006 e; 22,1\% (11,23 - 36,86) em 2010. Após o período de governo de Collor e FHC, ou seja, dos partidos de centro-direita, o índice de abstenção caiu, possivelmente em benefício de Lula e motivado pelo carisma do candidato. $\mathrm{O}$ menor índice de abstenção, e baixa amplitude, no pleito de 2006 revelam o bom desempenho de Lula no seu primeiro mandato, ultrapassando os problemas das denúncias de corrupção do ano de 2005. Se por um lado às abstenções no período estudado estiveram próximo de $20 \%$, o que demonstra uma variação não tão significante, a distribuição das mesmas no estado do Paraná parece ser marcante (figura 6). A região central do estado sempre apresentou os maiores índices de abstenção (superior a 30\%). Os 
BARROS, O.N.F. et al. Análise cartográfica do confronto presidencial ... municípios com percentuais abaixo de $10 \%$ são pouco significativos e com ocorrência aparentemente aleatória.
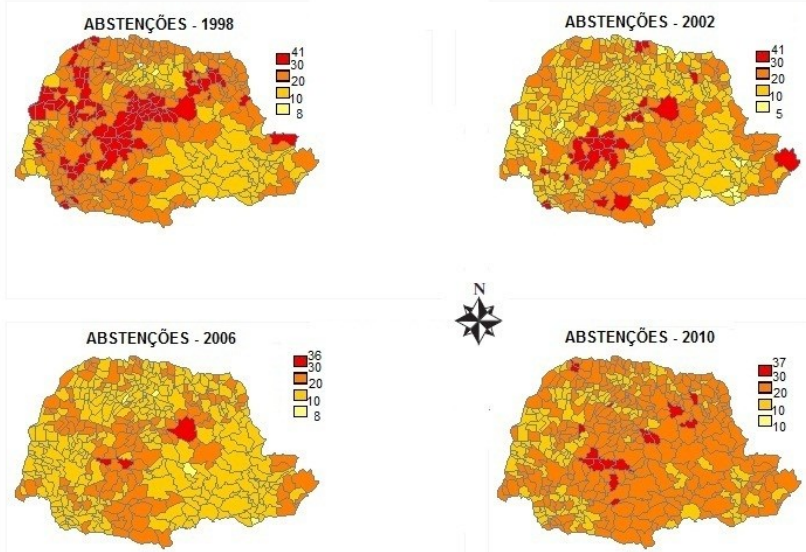

Fonte: TSE

Figura 1: Percentual de abstenções nos municípios do Paraná nas eleições de 1998, 2002, 2006 e 2010.

São nas classes de $10-20$ e $20-30 \%$ que encontramos as maiores ocorrências municipais. Nas eleições em que Lula foi vitorioso, a classe $10-20 \%$ foi a mais representativa, com distribuição generalizada no estado, exceto nas zonas costeira e central que apresentaram índices mais elevados. A classe $20-$ $30 \%$, com alta ocorrência de municípios em 1998, diminuiu sua importância em 2002 e 2006, mas cresce significativamente em 2010, representando agora 63\% dos municípios do estado, ganhando espaço sobre a classe imediatamente inferior. Por fim a classe de 30 - 40\% que em 1998 representava 24\% das ocorrências municipais, sobretudo na região central, conforme já assinalado, vê sua frequência diminuir nos pleitos seguintes chegando ao ínfimo valor de estar presente em apenas três municípios em 2006, o que demonstra mais uma vez o grande interesse que o eleitor teve em participar para reeleger o presidente Lula. 
BARROS, O.N.F. et al. Análise cartográfica do confronto presidencial ...

O Paraná, no quesito abstenções, representa parcialmente o microcosmo brasileiro. Sua região central parece com o Norte/Nordeste do país com suas fortes taxas de abstenção, enquanto grande parte do estado está integrada a maior parte do comportamento das regiões Sul e Sudeste.

\section{Geografia eleitoral dos candidatos do PT no Paraná}

Nas três eleições entre 1989 e 1998 Lula sempre chegou à segunda posição; $17,2 \%$ dos votos no primeiro turno de $1989,47 \%$ no segundo, 27\% em 1994 e 31,7\% em 1998. Segundo Waniez (2002, p. 354) a distribuição dos votos em favor de Lula na eleição de 1989 é forte em grande número das capitais, e em áreas de grande desenvolvimento industrial. Lula tem fraco desempenho na maior parte da região Sul e do Centro-Oeste. Em 1998 Lula apresenta um melhor desempenho na região Sul do país, devido à transferência de votos de Brizola que, foi candidato à vicepresidente na sua chapa. No estado do Paraná seus melhores resultados são no sudoeste, nos pleitos de 1989, 1994 e 1998. Waniez (2002) analisando a geografia eleitoral do Brasil no período 1989-1998 deixa clara a relativa estabilidade dos territórios eleitorais conquistadas pelos principais candidatos e a existência de estruturas sociais e ideológicas correspondentes.

"La mise en évidence d'une certaine stabilité des espaces électoraux conquis par les principaux candidats aux élections présidentielles brésiliennes au cours de la période 1989-1998 constitue en soi un résultat encourageant pour qui cherche à décrire et comprendre la géographie électorale de ce pays. On dispose ainsi d'une série d'observations empiriques couvrant la totalité du territoire national qui confirment l'existence de structures sociales et idéologiques qui reflètent l'organisation de territoires régionaux identifiables, et cela de manière relativement indépendante des alliances politiques circonstancielles. Ainsi, Collor et FHC occupent leurs meilleures positions dans les vastes espaces du Brésil intérieur et sur le littoral 
BARROS, O.N.F. et al. Análise cartográfica do confronto presidencial ...

du Nordeste. Lula, au contraire, fait le plein des voix dans les principales capitales des États de la Fédération, y compris dans la région Nordeste, et dans les régions Sudeste et Sud notamment, mais pas seulement, dans les grands bassins industriels" (WANIEZ, 2002, p.359).

Ainda que o PT tenha ganhado nas três últimas eleições presidenciais (2002, 2006 e 2010), o estado do Paraná não é aquele em que a centro-esquerda tem seu melhor desempenho. No quadro 1 podemos apreciar que apenas em 2002 o PT foi vitorioso no Paraná. Tal fato, sem dúvida, está associado à avaliação negativa do governo de FHC entre 1998 e 2002, ao pouco carisma do candidato do PSDB (José Serra) diante de Lula e a estratégia petista de ampliação das coligações (mais a direita) e mudança do discurso eleitoral (menos radical).

Quadro 1: Paraná - Votos válidos, votos no PT e votos no PSDB nas eleições presidenciais 1998 - 2010.

\begin{tabular}{|l|c|c|c|}
\hline \multicolumn{1}{|c|}{ ELEIÇÕES } & $\begin{array}{c}\text { VOTOS } \\
\text { VÁLIDOS }\end{array}$ & $\begin{array}{c}\text { VOTOS } \\
\text { NO PT }\end{array}$ & $\begin{array}{c}\text { VOTOS NO } \\
\text { PSDB }\end{array}$ \\
\hline 1998 & 4.205 .489 & $1.168 .636(28 \%)$ & $2.491 .549(59 \%)$ \\
\hline $2002-1^{\text {o }}$ Turno & 5.067 .229 & $2.540 .328(50 \%)$ & $1.367 .384(27 \%)$ \\
\hline $2002-2^{\circ}$ Turno & 4.946 .625 & $2.929 .427(59 \%)$ & $2.017 .198(41 \%)$ \\
\hline $2006-1^{\circ}$ Turno & 5.571 .418 & $2.111 .589(38 \%)$ & $2.953 .572(53 \%)$ \\
\hline $2006-2^{\text {o }}$ Turno & 5.408 .120 & $2.663 .423(49 \%)$ & $2.744 .697(51 \%)$ \\
\hline $2010-1^{\circ}$ Turno & 5.935 .001 & $2.311 .239(39 \%)$ & $2.607 .664(44 \%)$ \\
\hline $2010-2^{\text {o }}$ Turno & 5.819 .302 & $2.593 .086(44 \%)$ & $3.226 .216(55 \%)$ \\
\hline
\end{tabular}

Candidatos do PSDB: em 1998 - FHC, em 2002 e 2010 - José Serra e em 2006 - Geraldo Alckmin.

Candidatos do PT: em 1998, 2002 e 2006 - Lula e, em 2010 - Dilma Rousseff.

Da mesma maneira que na figura 1 os quatro cartogramas da figura 2 foram concebidos de forma a manter as legendas diretamente comparáveis. Na primeira classe aparecem os valores de mínimo até $25 \%$, na segunda entre 25 e $50 \%$, na terceira entre 
BARROS, O.N.F. et al. Análise cartográfica do confronto presidencial ...

50 e $75 \%$ e, na quarta entre 75 e o máximo. Para a seleção desses intervalos de legenda consideramos que menos de $25 \%$ de votos em um município, no segundo turno, representa um desempenho eleitoral baixo, de 25 até $50 \%$ desempenho médio, de 50 até $75 \%$ bom e acima de $75 \%$ ótimo.

Das quatro eleições em análise, a de 1998 é aquela em que Lula apresenta o pior desempenho global. Suas bases eleitorais mais significativas estão restritas ao sudoeste do estado e em uma extensão no oeste da região de Curitiba. A eleição de 2002 representa o momento de maior expansão territorial dos votos próPT. Ainda que seja preservada sua maior força nas regiões sudoeste e sul do estado, o avanço percentual de Lula ocorre praticamente em todos os municípios. A classe de maior ocorrência é a de $50-75 \%$, chegando mesmo a ter mais de $75 \%$ dos votos em treze municípios, esses restritos ao sudoeste. Nas eleições seguintes o PT perde progressivamente apoio eleitoral (de 59\% em 2002, passa para 49\% em 2006 e 44\% em 2010) e vê sua base territorial se encolher em direção ao sudoeste.

Podemos perceber que o sudoeste é uma região com votos mais a esquerda, desde as eleições de 1989 em que Brizola ali tinha seus melhores resultados no Paraná, até o bom desempenho de Dilma em 2010. O sudoeste é uma região de pequenos produtores, com forte vínculo cooperativo e de lutas sociais. Local de origem de alguns dos deputados petistas para a Assembleia Legislativa Estadual. Devemos lembrar que, em 1998, Lula ainda representava de maneira clara movimentos sociais como, por exemplo, o MST, o que lhe conferia grande apoio em municípios com agricultura familiar. Ao longo do período estudado a região do vale do Ribeira de Iguape, na fronteira com o estado de São Paulo consolida também uma influência do PT. Essa região, assim como, a central do estado apresenta os piores índices econômicos e, os eleitores possivelmente estavam descontentes com as poucas políticas sociais do governo FHC. 
BARROS, O.N.F. et al. Análise cartográfica do confronto presidencial ...
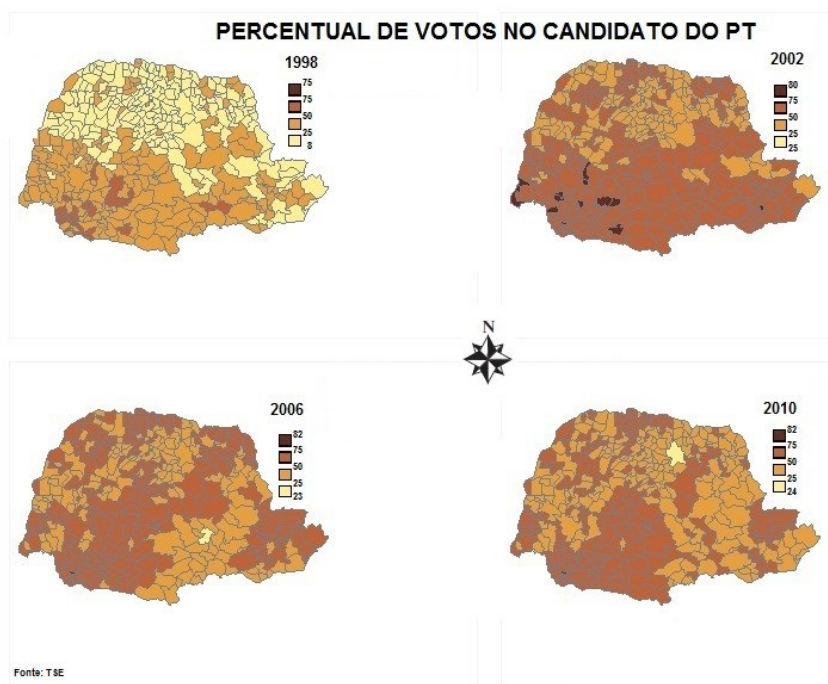

Figura 2: Percentual de votos no PT - municípios do Paraná nas eleições de 1998, 2002, 2006 e 2010.

\section{Geografia eleitoral dos candidatos do PSDB no Paraná}

Nas eleições de 1989, 1994 e 1998 ganharam os candidatos sustentados pela direita e centro-direita. Segundo Waniez (2002, p. 351) a distribuição dos votos em favor de FHC no plano nacional se parece muito com aquela obtida por Collor: forte implantação na região Nordeste e no interior do país, fraca influência nas grandes cidades. Na eleição de 1989, Collor foi bem votado no norte do Paraná e esse padrão geográfico foi mantido por FHC em 1994 e 1998 (figura 3). Nesse período os resultados eleitorais de FHC demonstram uma forte estruturação espacial e temporal de suas bases eleitorais, tanto no plano nacional quanto estadual, mesmo se são observadas algumas modificações de menor amplitude. 
BARROS, O.N.F. et al. Análise cartográfica do confronto presidencial ...

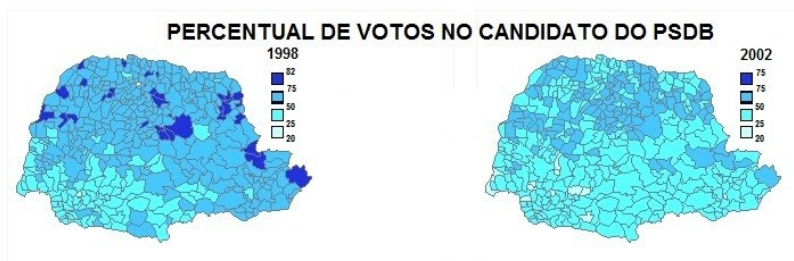

离
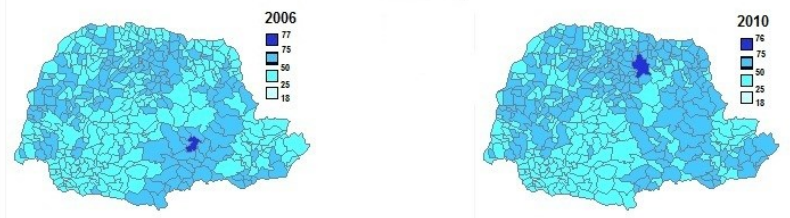

Figura 3: Percentual de votos no PSDB - municípios do Paraná nas eleições de 1998, 2002, 2006 e 2010.

A geografia dos votos nos candidatos do PSDB no período de 1998 até 2010 é de maneira geral um negativo fotográfico da figura 2, que representa os votos percentuais no PT. As expansões e retrações dos votos pró-PSDB são diretamente inversas a dos candidatos do PT. Em 2006 e 2010 chamam atenção os municípios Imbituva no sul e Londrina no norte, onde o PSDB obteve mais do que $75 \%$ dos votos. Salvo a eleição de 1998 em que o PSDB foi bem em grande parte do estado, as eleições seguintes marcam progressivamente uma consolidação territorial ao leste e norte do Paraná que em 2010 praticamente envolvem o sudoeste mais petista.

Nos três municípios com maior peso eleitoral do estado (Curitiba, Londrina e Maringá) o PSDB sempre foi o partido vencedor (salvo na eleição de 2002 em Curitiba); o que lhe confere grande vantagem, pois, esses três municípios juntos, representam $25 \%$ do colégio eleitoral paranaense. Na eleição de 1998, trezentos e quatro municípios, dentre os 399 , deram mais de $50 \%$ dos votos 
BARROS, O.N.F. et al. Análise cartográfica do confronto presidencial ...

ao PSDB. O partido vê esse grande percentual de apoio se reduzir nas eleições seguintes, com aproximadamente $60 \%$ dos municípios conferindo ao partido entre 25 e $50 \%$ dos votos. Finalmente fica demonstrada a importância de ganhar nos três grandes municípios do estado, fato que já havia sido assinalado por nós quanto às eleições para o governo do estado (BARROS, 2010 a e b).

\section{Conclusões}

Os padrões territoriais revelados ao longo do tempo permitiram mostrar tendências ideológicas do eleitorado. Considerando que Collor de Mello e os candidatos do PSDB foram apoiados por forças políticas de direita, enquanto Lula e Dilma de esquerda perceber-se que em certas regiões do Paraná o eleitorado tende a votar de maneira mais conservadora, enquanto em outras, de maneira mais progressista. Nas regiões mais desenvolvidas economicamente do estado, como o norte e leste paranaense, o eleitorado apoiou de maneira mais sustentável os candidatos da centro-direita. Mas regiões com maior participação de agricultores familiares e de municípios com baixo desempenho econômicos os votos tenderam para o apoio do PT.

O estado do Paraná representa, no período estudado, um microcosmo do Brasil e, até chega a antecipar as mudanças de comportamento do eleitorado em 2006 que ao nível nacional marca uma nova clivagem, agora de orientação norte-sul, com Lula sendo bem votado nas regiões Norte e Nordeste, mais pobres, com menor nível de educação e renda. A geografia eleitoral do Paraná é mais estável que aquela apresentada pelo Brasil, mas, demarca claramente as opções políticas dos setores socioeconômicos paranaense.

\section{Agradecimento}

Agradecemos a Fundação Araucária pelo patrocínio ao Projeto de Pesquisa "PARANÁ 2010: NOVAS ELEIÇÕES VELHOS CANDIDATOS". 
BARROS, O.N.F. et al. Análise cartográfica do confronto presidencial ...

\section{Referências bibliográficas}

AMORIM, Paulo Henrique, PASSOS, Maria Helena. PLIMPLIM: a peleja de Brizola contra a fraude eleitoral. São Paulo, Conrad Editora do Brasil. 2005

AVELAR, Lúcia, WALTER, Maria Inez Machado Telles. Lentas mudanças: o voto e a política tradicional. Opin. Pública, 14, 1: 96122. 2008

BARROS, Omar Neto Fernandes. Eleições Majoritárias No Paraná: Período 1998 - 2006, in: II Simpósio Sobre Pequenas Cidades - XXVI Semana De Geografia "As Pequenas Cidades Na Geografia Brasileira". Londrina, de 27 a 29 de setembro de 2010, EDUEL - Editora da Universidade Estadual de Londrina. 2010

BARROS, Omar Neto Fernandes. Eleições para Governador no Paraná: Primeiros Resultados do Pleito 2010, in: II Simpósio Internacional - Caminhos Atuais da Cartografia Geográfica: O mapa como forma de expressão das geografias. Realizado nos dias 01 a 04 de dezembro de 2010. Departamento de Geografia da Universidade de São Paulo - FFLCH - USP. 2010

BORGES, André. Já não se fazem mais máquinas políticas como antigamente: competição vertical e mudança eleitoral nos estados brasileiros. Rev. Sociol. Polit., Curitiba, 18, 35: 167-188. 2010

FLEISCHER, Davis. As eleições municipais no Brasil: uma análise comparativa (1982-2000). Opin. Pública, Campina, 1: 80-105. 2002.

GAJARDONI, Almyr. Idiotas \& Demagogos: Pequeno Manual de Instrução da democracia. Ateliê Editorial. Cotia. 2002. 
BARROS, O.N.F. et al. Análise cartográfica do confronto presidencial ...

JACOB, Cesar. Romero, HESS, Dora Rodrigues, WANIEZ, Philippe e BRUSTLEIN, Violette. As eleições presidenciais no Brasil pós-ditadura militar: continuidade e mudança na geografia eleitoral. $\boldsymbol{A} \boldsymbol{L} \boldsymbol{C E} \boldsymbol{U}$, Rio de Janeiro 1, 1:102-151. 2000.

JACOB, Ceasr. Romero, HESS, Dora Rodrigues, WANIEZ, Philippe e BRUSTLEIN, Violette. A eleição presidencial de 2006 no Brasil: continuidade política e mudança na geografia eleitoral. $\boldsymbol{A L C E U}$, Rio de Janeiro, 10, 19: 232-261. 2009.

KATUTA, Ângela Massumi. A Geografia, A Cartografia, A Descrição E A Alienação, in: Anais do X Encontro de Geógrafos da América Latina - 20 a 26 de março de 2005 - Universidade de São Paulo. 2005.

KINZO, Maria D’Alva, BRAGA, Maria do (org.) Eleitores e representação partidária no Brasil. Associação Editora Humanitas, São Paulo. 2007.

MARCHAL, Odile, THÉRY, Hervé, WANIEZ, Philippe. La géographie électorale du Brésil après l' élection présidentialle de 1989. Cah. Sci. Hum, Paris, 28, 3: 535-554. 1992.

MARTINELLI, Marcelo. Mapas da geografia e cartografia temática. $5^{\mathrm{a}}$ ed., $2^{\mathrm{a}}$ Reimpressão, São Paulo, Contexto. 2010.

SOARES, Glaúcio Ary Dillon; TERRON, Sonia Luiza. Dois Lulas: a geografia eleitoral da reeleição (explorando conceitos, métodos e técnicas de análise geoespacial). Opin. Pública, Campinas, 14,2: 269-301. 2008.

THÉRY, Hervé, MELlO, Neli Aparecida de. Atlas do Brasil Disparidades e Dinâmicas do Território. São Paulo: Editora da Universidade de São Paulo, 312p. 2008. 
BARROS, O.N.F. et al. Análise cartográfica do confronto presidencial ...

WANIEZ, Philippe. Les données et le territoire au Brésil. Mémoire pour l'obtention du Diplôme d'Habilitation à Diriger des Recherches en Géographie Humaine. Université Paris X Nanterre. 2002. Disponível no site pessoal do autor (http://philcarto.free.fr). Acesso em 28/02/2013.

Recebido em dezembro de 2012 Aceito em junho de 2013 